\title{
Evolution of Russian Macroeconomic Policy in Three Crises
}

The paper contains comparative analysis of macro policies carried out on the eve and in the course of the three crises episodes (1998, 2008-2009, and 2014-2015). Efficiency of alternative policies pursued in these cases is indirectly characterized by collating sizes of adverse shocks, resources used by the government and the central bank, and economic performance (primarily output decline, unemployment, etc). A brief overview of key steps in the evolution of monetary and fiscal policies implemented over the last 20 years is suggested. The author is arguing that in the first two crisis episodes main efforts were aimed at maintaining macro stability despite changes in fundamental conditions. The priority of the new macroeconomic stance, on the contrary, is finding new equilibrium adequate to the new situation. The findings of the earlier comparative analysis are used to illustrate advantages of the new approach.

Keywords: financial crisis, exchange rate policy, fiscal policy, Russian economy.

JEL Classification: E5, G01, H6.

О.А. Замулин

НИУ ВШЭ, Москва

Журнал НЭА, №1 (29), 2016 ,

Россия в 2015 г.: рецессия со стороны преАложения

c. $181-185$

Наблюдаемые факты о российской рецессии 2015 г., в первую очередь отсутствие скачка безработицы и ускорение инфляции, заставляют сделать вывод, что данная рецессия вызвана ограничениями со стороны предложения, а не падением совокупного спроса. Хотя трудно однозначно назвать природу этих ограничений, они могут быть связаны, например, с выросшим административным давлением на бизнес и повышением монополизации экономики на фоне общей стагнации, длящейся уже несколько лет. В этих условиях возможности стандартной денежной и бюджетной политики являются ограниченными. Для выхода из стагнации и возобновления роста необходимо проводить структурные реформы, направленные на развитие конкуренции и установление верховенства права.

Ключевые слова: Россия, речессия.

Классификация JEL: E3, E5, E6.

Прежде чем давать рекомендации по оптимальной политике, необходимо сначала четко определить, от какой болезни страдает российская экономика. Падение экономики почти на $4 \%$ в 2015 г. может натолкнуть на мысль, что перед нами стандартная рецессия, вызванная падением совокупного спроса, которое, в свою очередь, было вызвано падением цен на нефть и санкциями, ограничившими российским компаниям доступ к кредиту. На такое падение рекомендуется, как правило, реагировать стимулированием экономики посредством денежной или бюджетной политики. Именно так и поступали российское правительство и Центральный банк, например, во время мирового кризиса, ударившего по России в конце 2008 г. Однако на этот раз ситуация другая. Перед нами - редкий случай рецессии со стороны предложения, а не спроса. Соответственно, реагировать на нее методами стимулирования бессмысленно. Более того, они могут нанести вред.

Начнем с того, что экономический рост в России остановился, самое позднее, в 2013 г., когда официальные темпы роста составили всего 1,3\%, что является неприемлемо низким показателем для страны со средним уровнем достатка, какой является Россия. Но еще более вероятно, что рост остановился в 2008 г. Если проанализировать данные российского ВВП, то излом тренда в 2008 г. виден очень отчетливо. Точно определить его момент, просто глядя на данные, сложно, поскольку период 2009-2012 гг. пришелся на кризисное падение 
и последовавшее восстановление, однако как только в 2012 г. экономика вышла на уровень 2008 г., она остановилась. Более того, многие аналитики обращали внимание на замедление промышленности еще в первом полугодии 2008 г., но затем внимание быстро переключилось на кризис (например, см. (Российская экономика..., 2009, разд. 3.2-3.3)).

В чем причина данного замедления? Оно явилось закономерным окончанием десятилетнего периода восстановительного роста 1999-2008-х годов. Свободные мощности, простаивающие после трансформационного спада 1990-1998-х годов, были загружены, занятость приблизилась к полной, а уровень ВВП на душу населения превысил позднесоветские показатели, и рост остановился. Легкий период әкономического роста, основанный на использовании старых мощностей, закончился. Дальнейший рост возможен только на основе роста производительности и масштабных инвестиций в новые мощности. Но для такого роста в России необходимо создать иную институциональную среду, благоприятную для ведения бизнеса, создания и расширения производства и внедрения новых технологий - то, чего за годы восстановительного роста так и не было сделано.

Таким образом, на мой взгляд, стагнация последних лет вызвана в первую очередь неблагоприятным бизнес-климатом, и началась она до появления таких внешних шоков, как экономические санкции и падение цен на нефть. И это - стагнация со стороны предложения, поскольку производственные возможности экономики перестали расти.

Но можно ли таким же образом объяснить и падение экономики в 2015 г.? Можно ли не только остановку роста, но и его дальнейшее падение объяснить стороной предложения, т.е. сокращением производственных возможностей? Или же это уже стандартная рецессия, вызванная падением спроса? Ответы на эти вопросы в значительной степени определят и оптимальную ответную политику.

На эту тему в ближайшие годы хотелось бы увидеть формальные эконометрические исследования, но пока их нет, приходится полагаться на наблюдаемые факты и здравый смысл.

Сначала рассмотрим гипотезу, согласно которой перед нами - отрицательный шок совокупного спроса. Механизм такого шока вполне очевиден: падение цен на нефть сократило располагаемые доходы населения, а санкции ограничили доступ корпораций к кредиту. При таком шоке мы должны наблюдать падение экономики ниже долгосрочного тренда, что выражается в росте безработицы и сокращении загрузки мощностей. Кроме того, должна замедляться инфляция.

Но даже беглый взгляд на данные убеждает, что признаков шока спроса в российской экономике нет. По данным Росстата, уровень безработицы в течение всего 2015 г. оставался ниже $6 \%$, только на полпроцента превышая исторический минимум, а инфляция оказалась самой высокой с 2008 г. При этом напомним: в 2009 г. мы наблюдали и скачок безработицы, и резкое замедление инфляции. Высокую инфляцию 2015 г. можно в значительной степени объяснить обесценением рубля зимой 2014-2015 гг. (в свою очередь, вызванным падением цен на нефть - шоком предложения), но даже это очевидное объяснение нельзя считать полностью удовлетворительным. Во-первых, за год сильнее обычного подорожали не только товары, но и услуги, импортная компонента в которых значительно меньше. Во-вторых, при падении совокупного спроса инфляция должна замедлиться даже на фоне обесценения валюты, что было отчетливо видно в 2009 г., когда инфляция замедлилась с 13,3 до 8,8\%. В-третьих, высокая инфляция начала 2015 г., замедлившись к середине года, устойчиво возобновилась осенью без какоголибо соразмерного обесценения валюты. Во втором полугодии курс стал снова падать вслед за ценой на нефть, но это падение просто компенсировало укрепление рубля в первом полугодии, и к концу года курс доллара вышел на уровень начала года.

Таким образом, динамика российской экономики в 2015 г. совсем не похожа на шок совокупного спроса. Наоборот, падение экономики при неизменной безработице и ускорившейся инфляции создает впечатление, что перед нами - шок совокупного предложения. Это значит, что не экономика упала ниже долгосрочного тренда, а тренд сдвинулся вниз. Дополнительным аргументом в пользу этой гипотезы является тот факт, что экономика начала сокращаться уже в третьем квартале 2014 г., т.е. до падения чен на нефть.

Проблема гипотезы шока совокупного предложения заключается в том, что ее гораздо сложнее обосновать с позиции здравого смысла. Ведь эта гипотеза означает, что сократились производственные возможности экономики: либо сократилось число факторов производства (труда и капитала), либо экзогенно упала их производительность. Иными словами, выросли реальные издержки производства. Обоснование таких шоков является слабым местом теории реальных экономических циклов, которая считает именно сто- 
рону предложения основным источником экономических флуктуаций (см., например, обсуждение этой проблемы в (Blanchard, 2009, p. 209-228)).

Однако есть веские аргументы в пользу того, что именно такое редкое явление, как отрицательный шок совокупного предложения, имело место в России в 2014-2015 гг. Речь идет не о каком-то одном событии, а о ряде факторов, каждый из которых увеличивал издержки производства или сокращал производственные мощности. Все эти факторы трудно оценить количественно, но, я надеюсь, дальнейшие исследования смогут формально проверить правильность данной гипотезы.

Итак, какие факторы в 2014-2015 гг. могли способствовать сокращению совокупного предложения и росту реальных издержек? Я предполагаю, как минимум, следующее:

- падение цены на нефть, которое является не столько шоком спроса, сколько шоком именно предложения, так как сужает доступность импортного сырья и оборудования и повышает цены;

- уменьшение запаса основных капитальных мощностей вследствие сокращения инвестиций, начавшегося еще в 2013 г;;

- санкции против России, лишившие российские корпорации доступа не только к кредиту, но и к технологиям;

- рост издержек производства вследствие усиления административного давления на бизнес;

- ответные российские санкции, ограничивающие конкуренцию с импортом и вследствие этого расширяющие монопольную власть российских фирм.

Падение совокупного предложения не исключает также возможности и одновременного падения спроса. Во-первых, в равновесии эти две величины равны друг другу, так что падение предложения обязано было вызвать и подстройку спроса. Во-вторых, оба шока могли произойти одновременно. Но главный вывод заключается в том, что в результате экономика не оказалась в отрицательном разрыве выпуска (ниже потенциального ВВП). Скорее, упал сам потенциальный ВВП.

\section{Возможности денежной политики}

Если исходить из того что перед нами рецессия со стороны предложения и экономика не находится ниже своего потенциального уровня, то денежной политикой многого достичь не удастся. Денежная политика действенна только тогда, когда в экономике есть избыточные ресурсы и занять их мешает низ- кий совокупный спрос и высокие процентные ставки.

Тем не менее призывы понизить процентные ставки и увеличить кредитование экономики звучат все время. Чем же чревато такое ослабление политики в текущей ситуации?

Важно помнить, что Центральный банк РФ на денежном рынке оперирует краткосрочными процентными ставками, в то время как предприятия берут кредиты на долгий срок. Долгосрочные процентные ставки зависят как от текущих краткосрочных ставок, так и от ожидаемой будущей инфляции. Таким образом, Центральный банк РФ, понижая процентные ставки, может стимулировать кредитную активность только при условии, что он не создаст своими действиями ожиданий роста инфляции в будущем. Однако при полной занятости именно такие ожидания и возникнут дополнительные деньги в экономике не смогут стимулировать производство, а выльются только в рост цен.

Если проанализировать ставки по долгосрочным кредитам в 2015 г., то нет свидетельств того, что понижение ключевой ставки серьезно повлияло на ставки по банковским кредитам. Так, по данным Банка России, средняя кредитная ставка на срок более трех лет для нефинансовых предприятий снизилась немногим более чем на один процентный пункт с января по ноябрь (с 14,87 до 13,57\%), в то время как ключевая ставка была понижена за то же время с 17 до $11 \%$ в августе, где и остается до сих пор (т.е. на уровне ниже инфляции). Это означает, что банковский сектор по-прежнему считает высокими инфляционные риски, и дальнейшее понижение ключевой ставки может дать обратный эффект - долгосрочные ставки могут даже повыситься.

Таким образом, единственное, что остается Банку России - продолжать политику таргетирования инфляции и планомерно понижать инфляционные ожидания, для того чтобы снизить долгосрочные процентные ставки. Инфляция в последние месяцы 2015 г. и в первом месяце 2016 г. оставалась на высоком уровне (около $1 \%$ в месяц). В этих условиях цель таргетирования инфляции означает, как минимум, отказ от снижения ключевой ставки в ближайшей перспективе. Но надо быть готовым и к тому, что ставку придется повышать.

\section{Возможности бюджетной политики}

Другой противоциклической политикой обычно считается бюджетная - увеличение государственных расходов или снижение налогов в периоды рецессий. Даже без специ- 
альных активных действий со стороны правительства бюджетная политика, как правило, автоматически оказывается противоциклической, в силу того что налоговые сборы снижаются из-за сокращения әкономики, а государственные расходы остаются на изначально запланированном уровне. Таким образом, на время рецессии образуется бюджетный дефицит. Именно эта логика и диктовала накопление резервного фонда в период высоких цен на нефть - создание сбережений, которые можно тратить в период, когда цены на нефть упадут.

Однако Правительство РФ не следует данной стратегии - государственные расходы не увеличиваются, а, наоборот, сокращаются, чтобы избежать бюджетного дефицита. Так, 2016 г. начался с 10\%-ного секвестра федерального бюджета. Насколько разумны такие действия, противоречащие, на первый взгляд, стандартной логике?

Проблема заключается в том, что противоциклическая бюджетная политика разумна во время рецессий, вызванных падением совокупного спроса и имеющих временный характер. Государственные расходы в таких случаях позволяют сократить безработицу, привлекая высвободившуюся рабочую силу на общественно-важные работы либо сокращая налоговое бремя и тем самым стимулируя расходы населения.

Однако если падение вызвано стороной предложения и занятость остается близкой к полной, такие меры не возымеют эффекта. Увеличение расходов в одном месте неминуемо означает их сокращение в другом месте, так как производственные возможности экономики не увеличились, а свободных ресурсов нет. Таким образом, возможности активной бюджетной политики также оказываются ограниченными.

Но оправдывает ли данная логика проводимое сокращение расходов? Ведь, как минимум, государство может сохранять свои расходы на прежнем уровне, а не уменьшать их, усугубляя проблему. С этим аргументом можно было бы согласиться при условии долгосрочной стабильности бюджета. Можно позволить себе дефицит бюджета, если есть уверенность в том, что в не слишком отдаленном будущем дефициты снова сменятся профицитами.

К сожалению, это условие в сегодняшней России не выполняется. При сохранении текущего уровня расходов российский бюджет может стать профицитным только при быстром росте экономики и росте цен на нефть. Более того, по некоторым расчетам, обязательства, взятые российским руковод- ством на будущее, означают огромные бюджетные дефициты в будущем - даже без всякого кризиса (см., например, (Goryunov et al., 2013)). Да и ожидать восстановления экономики не приходится - даже в маловероятном случае снятия санкций структурные проблемы, вызвавшие замедление, начавшееся в 2008 или в 2013 г., никуда не уйдут, и российская экономика обречена на многолетнюю стагнацию. А если верить основной версии причин падения цены на нефть - рост предложения нефти вследствие сланцевой революции и падение спроса на нее вследствие замедления роста в развивающихся странах, - то и падение цен на нефть является долгосрочным явлением. Таким образом, приходится признать, что прежний уровень государственных расходов Россия больше себе позволить не может (независимо от того, был ли этот уровень изначально оправдан).

\section{Антикризисная политика}

Если задаться вопросом, что же должно делать государство для выхода из кризиса, то в первую очередь следует понять, что в текущих условиях означает такой выход. Восстановление экономики до уровня 2014 г., когда началось падение? Или выход на траекторию роста в 5-6\% в год, необходимую для того чтобы российская экономика снова начала догонять развитые страны и увеличивать свою долю в мировом ВВП (с 2008 г. эта доля сокращалась, так как экономика России росла медленнее мировой)?

Из изложенного выше ясно, что никаких мер, которые дадут быстрый эффект, ни у правительства, ни у Центрального банка попросту нет, Россия обречена на многолетнюю стагнацию. Проблемы экономики имеют структурный характер, и никакие краткосрочные методы стимулирования не могут работать. Пожалуй, единственное, что может дать относительно быстрый эффект, - отмена антисанкций, которая вернет конкуренцию на рынки продовольственных товаров и понизит цены, повысив реальные доходы населения.

В остальном необходимые действия это меры, направленные на улучшение инвестиционного климата, ведь для возобновления роста России в первую очередь нужны инвестиции, которые позволят накапливать капитальные мощности и внедрять новые для России технологии (как инженерные, так и управленческие). Эти меры неоднократно называли различные әксперты, в том числе в рамках обсуждения антикризисной политики правительства. Перечислим еще раз основные из них: 
- построение эффективной и независимой судебной системы, способной защищать права собственности бизнеса;

- снижение уровня коррупции и административного давления на бизнес, дебюрократизация;

- повышение уровня конкуренции в российской экономике, посредством в том числе приватизации государственных производственных активов.

К этим мерам, ориентированным на институциональные преобразования, стоит добавить меры, связанные с государственными вложениями в человеческий капитал (образование и здравоохранение) и инфраструктуру вместо проводимого сейчас наращивания военных расходов.

Падение цен на нефть в некотором смысле дает России шанс провести указанные преобразования. Именно высокие цены на нефть в прежние годы обеспечивали обилие дешевых денег, которыми можно было гасить социальное напряжение и которые стимулировали рентоориентированное поведение чиновников и рост коррупции. Теперь этой ренты больше нет, и единственная возможность повышения благосостояния общества развитие собственного производства. Но получится ли воспользоваться этим шансом, покажет время.

\section{ЛИТЕРАТУРА}

Российская экономика в 2008 году: тенденции и перспективы (2009). Выпуск 30. M: Институт экономики переходного периода.

Blanchard O. (2009). The State of Macro // Annual Review of Economics, Annual Reviews. Vol. 1(1). P. 209-228.

Goryunov E., Kazakova M., Kotlikoff L., Mamedov A., Nesterova K., Nazarov V., Grishina E., Trunin P., Shpenev A. (2013). Russia's Fiscal Gap. NBER WP No. 19608.

REFERENCES (with English translation or transliteration)

Russian Economy in 2008: Trends and Outlooks (2009). Issue 30. M: Institute for the Economy in Transition (in Russian).

Blanchard O. (2009). The State of Macro. Annual Review of Economics, Annual Reviews 1(1), 209-228.

Goryunov E., Kazakova M., Kotlikoff L., Mamedov A., Nesterova K., Nazarov V., Grishina E., Trunin P., Shpenev A. (2013). Russia's Fiscal Gap. NBER WP No. 19608 .

Поступила в редакиию 16 февраля 2016 года

\section{O.A. Zamulin}

National Research University Higher School of Economics, Moscow, Russia

\section{Russia in 2015: a Supply-Side Recession}

The observed facts about Russia's 2015 recession, such as acceleration of inflation and lack of increase in unemployment, lead to conclusion that this recession was caused by supply-side restrictions rather than a fall in aggregate demand. Although it is not easy to identify these restrictions, they may be connected with such things as increased administrative pressure on business or increased monopolization of the economy in combination with a general economic stagnation that had been lasting for several years already. Under these circumstances, standard monetary and fiscal policies cannot do much. Rather, revival of economic growth requires structural reforms aimed at development of competitive economic environments and rule of law.

Keywords: Russia, recession.

JEL Classification: E3, E5, E6. 